Reference

JONES, G. H. (1990) A casualty of the ambulance dispute. Psychiatric Bulletin, 14, 402.

\section{How to get in touch with patients in a developing country}

\section{DeAR SIRS}

When establishing a new psychiatric service, the early priorities are to obtain adequate buildings, to ensure supplies of medication and to train staff. Any spare time that a psychiatrist may have for treating patients is likely to be occupied by a middle class clientele. The next stage, exemplified by Dr Sidandi's (1990) description of a provincial service in Zimbabwe, is to get community treatment going. How should psychiatrists set about contacting patients? Persuading traditional healers to refer on suitable patients is a favoured method in Africa but is not possible everywhere.

An account is given here of my 1972 experience of holding out-patient clinics in rural areas of Dominica which may still be of interest as it was then virgin territory from a psychiatric point of view. There was a small, mainly custodial, unit for acutely disturbed patients run by nurses. There had been occasional visits to the island by psychiatrists employed by development agencies but there had been no regular community psychiatric service. The situation is now much improved thanks to the subsequent work of a Dominican psychiatrist, Dr John Royer.

Dominica is a West Indian island with a population at that time of about 70,000 , half of whom lived in the capital and the rest in scattered rural communities. Although small, it is so mountainous that travel between one part of the island and another was difficult. I held regular out-patient clinics in three rural areas separated from each other by at least an hour's drive. Each area had a cottage hospital, at which a district medical officer was based and a health centre staffed by between two and four district nurses. The latter had mostly been through the training programme run by the island's main hospital, which included little on psychiatry.

In one of the areas (Portsmouth) information was spread by hospital staff by word of mouth and patients were allowed to refer themselves to my clinic at the cottage hospital. In a second (Grand Bay) patients were referred by district nurses. In a third (Marigot) patients were initially referred by the district medical officer to a cottage hospital clinic but this appeared less successful than the method used in Grand Bay so a switch was made to district nurse referrals.

It may be seen from the Table that the doctor referred clinic was the least satisfactory as few patients complied with follow-up and the proportion of severely ill people seen was quite low. The doctor, although himself Dominican, was a recent arrival from another part of the island. Self referrals were often appropriate, but compliance with follow-up was again a problem. The best results were provided by district nurse referral, the two separate areas proving very similar.

This experience served to re-emphasise two truisms: first that psychiatrists are likely to get the best results if they work with people who may be

TABLE

\begin{tabular}{lccccc}
\hline & $\begin{array}{c}\text { Number of } \\
\text { new patients }\end{array}$ & $\begin{array}{c}\text { \% not } \\
\text { psychiatrically } \\
\text { ill }\end{array}$ & $\begin{array}{c}\% \text { mildly } \\
\text { ill }\end{array}$ & $\begin{array}{c}\% \text { asked to } \\
\text { reverely for } \\
\text { ill* }\end{array}$ & $\begin{array}{c}\text { follow-up } \\
\text { who failed } \\
\text { to do so }\end{array}$ \\
\hline $\begin{array}{c}\text { Portsmouth (self referrals) } \\
\text { Grand Bay (district } \\
\text { nurse referred) }\end{array}$ & $145^{* *}$ & 25 & 59 & 16 & 41 \\
$\begin{array}{c}\text { Marigot Hospital } \\
\text { (doctor referred) }\end{array}$ & 81 & 19 & 56 & 25 & 29 \\
$\begin{array}{c}\text { Marigot Health Centre } \\
\text { (district nurse referred) }\end{array}$ & 24 & 12 & 71 & 17 & 65 \\
\hline
\end{tabular}

*The criterion for 'severely ill' was that the patient might have been considered to require intensive day or in-patient treatment had this been available.

**The population of the Portsmouth area was greater than that of the other two. Accurate figures were not available, but it is likely that the proportion of patients seen per head of population was similar in each area and in the range 2-5 per hundred. 
psychiatrically naive but know their local communities well. Second that rural populations are quite capable of making appropriate self referral, although the curiosity factor ("let's see what the new doctor is like?') may waste a certain amount of time and some of the most ill patients may be missed. It is really not very different in the allegedly developed world.

Royal South Hants Hospital

C. M. H. NuNN

Southampton SO9 4PE

Reference

SIDANDI, P. (1990) Rehabilitation psychiatry: description of a provincial setting in Zimbabwe. Psychiatric Bulletin. $14,552-554$.

\section{Archibald Campbell Clark}

DeAR SIRS

If any of your readers knows of the whereabouts of an authentic portrait or photograph of Archibald Campbell Clark (d. 1901) I should be grateful if they would let me know. I am aware of the portrait plaque on the Pinel Memorial at the Royal Edinburgh Hospital. The information is required for a history of Hartwood Hospital of which Clark was the first Physician Superintendent.

JuLIAN Hodgson Librarian

Hartwood Hospital

Hartwood, Shotts

Scotland ML7 4LA

\section{Deaf patients at Rampton Hospital}

DEAR SIRS

Since Dr Roberts' pioneering work in establishing the group for deaf patients at Rampton Hospital (Psychiatric Bulletin, May 1990, 14, 279-282) it is pleasing to be able to report further developments.

Firstly, the Deaf Group as described by Dr Roberts continues to thrive and now forms a social club which meets fortnightly. Voluntary visitors who are also deaf join the group, forming an important source of contact with the local community and enhancing the development of deaf culture within the hospital. The hospital interpreter is now employed three days a week assisting staff in all departments in their communication with deaf patients. For example, the interpreter attends case conferences and ward reviews and is involved with staff in individual patient counselling sessions.
The hospital has recently employed a Sign Demonstrator who is also deaf. The Sign Demonstrator works principally for the Education Department, assisting the teaching staff in their daily classes with the deaf. The Sign Demonstrator is seen as an important role model for deaf patients, serving to remind them that they too can achieve in a predominantly hearing world.

Increasing staff awareness has led to a call for further education and training. This has been met by providing training workshops in 'Deaf Awareness' and these have been run in conjunction with the Royal National Institute for the Deaf. A number of such training events have been held in the hospital and have been attended by staff from many disciplines. There have also been training days for deaf patients in how to use an interpreter.

A significant number of staff in various disciplines are now acquiring British Sign Language (BSL). Classes are currently being run in the hospital by the Sign Demonstrator. A number of staff are now at Stage II of the CADCP. The services of a speech therapist are also available to patients with hearing impairments.

This list is not exhaustive. Attention is being paid to the use of hearing aids, Teletext televisions, minicom telephone communications etc. A Steering Group for the Deaf, which was established around the time of the initial group meetings, monitors developments within the hospital. Currently attention is being focused on the hard of hearing.

In conclusion the formation of the Deaf Group and the lessons learnt from it have not fallen on deaf ears.

Rampton Hospital

EMMET P. LARKIN

Retford, Notts DN22 OPD

\section{Psychiatry in bookshops}

\section{DEAR SIRS}

I was interested to read Dr Watts' letter (Psychiatric Bulletin, October 1990, 14, 630), in which he suggests we might take note of where bookshops choose to market their books on psychiatry.

In the medical library at the Towers Hospital, Leicester, Ellis \& Calne's Lecture Notes on General Surgery has languished for many years in the section on Sexual Deviations. I am told this is an artefact of the classification, not a librarian's parapraxis.

Carlton Hayes Hospital

Christopher MAloney 